\title{
Characteristics of air pollution events over Hotan Prefecture at the southwestern edge of Taklimakan Desert, China
}

\author{
LI Jingxin ${ }^{1}$, WANG Shigong ${ }^{2,3^{*}}$, CHU Jinhua ${ }^{3,4}$, WANG Jiaxin ${ }^{2}$, LI Xu ${ }^{3}$, YUE Man $^{3}$, SHANG \\ Kezheng ${ }^{3}$ \\ ${ }^{1}$ State Key Laboratory of Severe Weather, Chinese Academy of Meteorological Sciences, Beijing 100081, China; \\ ${ }^{2}$ Sichuan Key Laboratory of Plateau Atmosphere and Environment, College of Atmospheric Sciences, Chengdu University of \\ Information Technology, Chengdu 610225, China; \\ ${ }^{3}$ Gansu Key Laboratory of Arid Climate Change and Reducing Disaster, College of Atmospheric Sciences, Lanzhou University, \\ Lanzhou 730000, China; \\ ${ }^{4}$ Chongqing Meteorological Bureau, Chongqing 401147, China
}

\begin{abstract}
Hotan Prefecture is located at the southwestern edge of Taklimakan Desert, the world's largest shifting sand desert, of China. The desert is one of the main sources for frequent sand-dust weather events which strongly affect the air quality of Hotan Prefecture. Although this region is characterized by the highest annual mean $\mathrm{PM}_{10}$ concentration values that are routinely recorded by environmental monitoring stations across China, both this phenomenon and its underlying causes have not been adequately addressed in previous researches. Reliable pollutant $\mathrm{PM}_{10}$ data are currently retrieved using a tapered element oscillating microbalance (TEOM) 1400a, a direct real-time monitor, while additional concentration values including for $\mathrm{PM}_{2.5}$, sulfur dioxide $\left(\mathrm{SO}_{2}\right)$, nitrogen dioxide $\left(\mathrm{NO}_{2}\right)$, carbon monoxide $(\mathrm{CO})$ and ozone $\left(\mathrm{O}_{3}\right)$ have been collected in recent years by the Hotan Environmental Monitoring Station. Based on these data, this paper presents a comparison of the influences of different kinds of sand-dust weather events on $\mathrm{PM}_{10}\left(\right.$ or $\left.\mathrm{PM}_{2.5}\right)$ as well as the concentrations of other gaseous pollutants in Hotan Prefecture. It is revealed that the highest monthly average $\mathrm{PM}_{10}$ concentrations are observed in the spring because of the frequent occurrence of three distinct kinds of sand-dust weather events at this time, including dust storms, blowing dust and floating dust. The floating dust makes the most significant contribution to $\mathrm{PM}_{10}$ (or $\left.\mathrm{PM}_{2.5}\right)$ concentration in this region, a result that differs from eastern Chinese cities where the heaviest $\mathrm{PM}_{10}$ pollution occurs usually in winter and air pollution results from the excess emission of local anthropogenic pollutants. It is also shown that $\mathrm{PM}_{10}$ concentration varies within typical dust storms. $\mathrm{PM}_{10}$ concentrations vary among 20 dust storm events within Hotan Prefecture, and the hourly mean concentrations tend to sharply increase initially then slowly decreasing over time. Data collected from cities in eastern China show the opposite with the hourly mean $\mathrm{PM}_{10}$ (or $\mathrm{PM}_{2.5}$ ) concentration tending to slowly increase then sharply decrease during heavy air pollution due to the excess emission of local anthropogenic pollutants. It is also found that the concentration of gaseous pollutants during sand-dust weather events tends to be lower than those cases under clear sky conditions. This indicates that these dust events effectively remove and rapidly diffuse gaseous pollutants. The analysis also shows that the concentration of $\mathrm{SO}_{2}$ decreases gradually at the onset of all three kinds of sand-dust weather events because of rapidly increasing wind velocity and the development of favorable atmospheric conditions for diffusion. In contrast, changes in $\mathrm{O}_{3}$ and $\mathrm{NO}_{2}$ concentrations conformed to the opposite pattern during all three kinds of sand-dust weather events within this region, implying the inter transformation of these gas species during these events.
\end{abstract}

*Corresponding author: WANG Shigong (E-mail: wangsg@cuit.edu.cn)

Received 2017-10-20; revised 2018-05-11; accepted 2018-06-26

(C) Xinjiang Institute of Ecology and Geography, Chinese Academy of Sciences, Science Press and Springer-Verlag GmbH Germany, part of Springer Nature 2018 
Keywords: $\mathrm{PM}_{10}$ (or $\mathrm{PM}_{2.5}$ ) concentration; sand-dust weather events; gaseous pollutants; air pollution; Taklimakan Desert

Citation: LI Jingxin, WANG Shigong, CHU Jinhua, WANG Jiaxin, LI Xu, YUE Man, SHANG Kezheng. 2018. Characteristics of air pollution events over Hotan Prefecture at the southwestern edge of Taklimakan Desert, China. Journal of Arid Land, 10(5): 686-700. https://doi.org/10.1007/s40333-018-0096-9

\section{Introduction}

Increasing numbers of scientists have argued that sand-dust weather events represent a significant atmospheric environmental problem in China and are also common events in other regions globally (Rodríguez et al., 2001; Pederzolia et al., 2010). Data released by the Ministry of Environmental Protection of the People's Republic of China reveal that $\mathrm{PM}_{10}$ (or $\mathrm{PM}_{2.5}$ ) is a primary air pollutant that has influenced urban air quality in most cities nationally in recent years. A number of studies reveal that heavy $\mathrm{PM}_{10}$ (or $\mathrm{PM}_{2.5}$ ) pollution is usually driven by sand-dust weather events in the north of China, especially the northwest, where little excess emission from local anthropogenic pollutants are also observed (Wang et al., 1999; Zhuang et al., 2001; Wang et al., 2006; Feng et al., 2010). A number of other dust event-related investigations have also been conducted, including those addressing spatiotemporal variations in extreme events (Baltaci, 2017), climatological analyses (Guan et al., 2014), reasons underlying various long-term characteristics (Guan et al., 2017), dust transport (Chen et al., 2017; Khuzestani et al., 2017), radiative effects of such events on weather and regional climate (Spyrou et al., 2013), influences on the environment and air quality (Prospero et al., 2014), and parameterization of dust emissions within a global atmospheric chemistry-climate model (Astitha et al., 2012).

A sand-dust weather event can be generally defined as a weather phenomenon that comprises low horizontal visibility combined with high wind speed according to the observation criteria (China Meteorological Administration, 1979). Previous researchers have noted that sand-dust weather events tend to exhibit a range of different patterns across northern China including dust storms as well as blowing and floating dusts (Feng et al., 2011). These three different types can all be classified as sand-dust weather events; dust storms are the most severe of these and are generally defined as exhibiting relatively turbid air and reduced horizontal visibility (less than $1000 \mathrm{~m}$ ). Such events can be disastrous because a great deal of dust and sand are lifted by strong winds. The most intense 'black storms' may have maximal destructive power and can reduce horizontal surface visibility to less than $50 \mathrm{~m}$, sometimes even down to zero. Blowing dusts are the second strongest sand-dust weather events observed in this region and are formed by powerful winds that transport large volumes of dust and sand, which can reduce horizontal visibility to $1000-10,000 \mathrm{~m}$. The floating dusts are the weakest sand-dust weather events occurred in the region with fine sand-dust suspended in the lower troposphere during these events and with a horizontal visibility greater than $10,000 \mathrm{~m}$. These events generally occur when dust is carried by air flows in the middle and upper troposphere from a source upwind, in some cases when fine dust remains aerially suspended subsequent to a storm (Wang et al., 2005). If two or three patterns of sand-dust weather events occur within the same day, the most severe sand-dust weather event is regarded as the phenomenon of the day. In this study, a comparative analysis is conducted to explore the influences of these sand-dust weather events on air pollutant concentrations.

Temporal variations in pollutant characteristics that result from these three kinds of sand-dust weather events are evaluated in this study by using newly released data from monitoring stations with five minute temporal resolution. It is anticipated that a series of reference data from this study can be used to address the more significant influence of sand-dust weather events on local air quality, as well as to examine the characteristic differences in air pollution events that result from anthropogenic and natural sources.

\section{Study area}

Hotan Prefecture is located at the southwestern edge of the Taklimakan Desert of China (Fig. 1) in 
an extremely arid climate zone. The desert is the largest shifting desert in the world ( $\mathrm{Zu}$ et al., 2005) and one of the main sand-dust sources (Qian et al., 2004; Wang et al., 2005). The annual potential evapotranspiration in this area can be as high as $2480 \mathrm{~mm}$ while the mean annual precipitation is just around $35 \mathrm{~mm}$. A total of $63 \%$ of acreage within this prefecture is covered by desert. Statistical analysis of data from routine weather monitoring stations shows that Hotan Prefecture boasts the highest occurrence frequency of sand-dust weather events within China. This results in a high $\mathrm{PM}_{10}$ emission capacity because of intensive windblowing sand and dust activity (Wang and Jia, 2013). $\mathrm{PM}_{10}$ concentration of Hotan Prefecture resulted from natural sources is the highest in Xinjiang, China (Zhang et al., 2017). The annual mean value of the air pollution index (API) for Hotan Prefecture is the highest in 16 major cities in Xinjiang. Data show that the API values can be as high as 500 in the spring, while the $\mathrm{PM}_{10}$ concentration in the total suspended particulate (TSP) can be as high as $45 \%$ half of the time during this period. It is important to note that the bulk of the $\mathrm{PM}_{10}\left(\right.$ or $\left.\mathrm{PM}_{2.5}\right)$ pollutants seen in this region are from sand-dust weather events. The agriculture is the mainstay of the local economy and there is no chemical industry and large manufacturing plant in this region. As local anthropogenic emissions only contribute a small extent to $\mathrm{PM}_{10}$ concentrations, Hotan Prefecture is therefore a representative region in which to assess natural sources of air pollutants. Knowledge regarding the influence of different sand-dust weather events on pollutant concentrations currently remains very limited in this region.

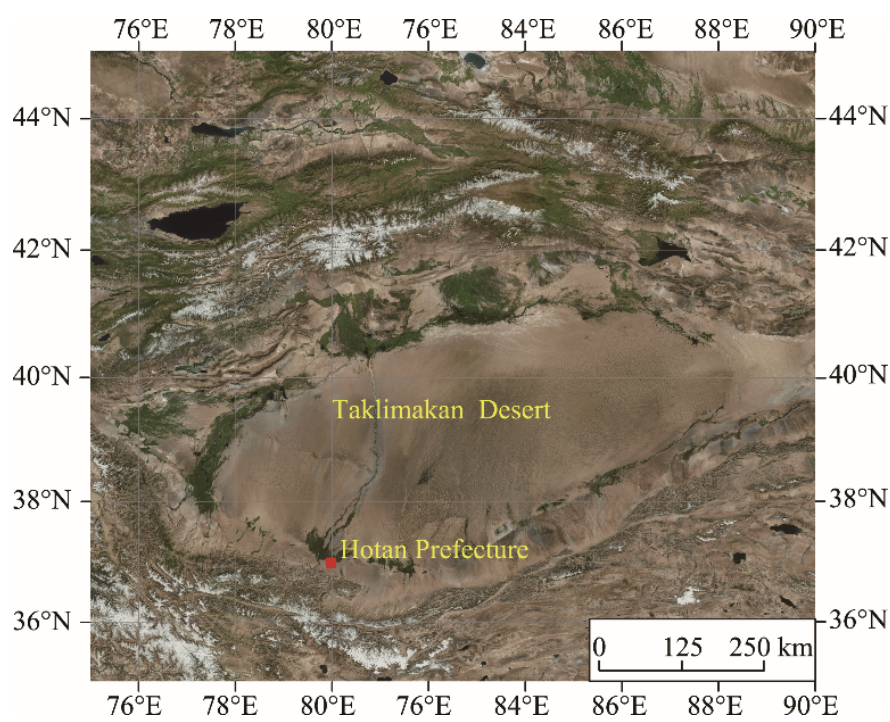

Fig. 1 Location of Hotan Prefecture

\section{Data and methods}

\subsection{Particulates and gaseous pollutants}

Concentrations of $\mathrm{PM}_{10}$ were measured using a tapered element oscillating microbalance (TEOM) 1400a atmospheric particulate monitoring instrument that was sited at an altitude of $1375 \mathrm{~m}$ in Hotan Prefecture $\left(37^{\circ} 08^{\prime} \mathrm{N}, 79^{\circ} 56^{\prime} \mathrm{E}\right)$. The TEOM instrument is able to continuously measure the concentration of airborne particles in real-time because it contains a filter membrane. As particles of aggregate on the membrane, the natural frequency of oscillations from the conical tube is correspondingly reduced such that the time resolution of measurement is just $5 \mathrm{~min}$. A microprocessor that is dependent on the quality and frequency variations of the filter membrane then calculates hourly mass flux and particle concentrations. The first $\mathrm{PM}_{10}$ concentration monitoring phase of this study was initiated on 9 January 2004 and ended on 9 August 2010; data are collected for $24 \mathrm{~h}$ each day over this period apart from some short breaks between 25 August 2004 and 25 January 2005, and between 19 July 2005 and 22 November 2005. The second PM 10 concentration monitoring phase was then initiated on 2 January 2015 and ended on 30 September 
2015. The concentrations of a number of other pollutants were also collected during this phase at the Hotan Environmental Monitoring Station according to the national standards (i.e., $\mathrm{PM}_{2.5}$, sulfur dioxide $\left(\mathrm{SO}_{2}\right)$, nitrogen dioxide $\left(\mathrm{NO}_{2}\right)$, carbon monoxide $(\mathrm{CO})$, and ozone $\left.\left(\mathrm{O}_{3}\right)\right)$, while $\mathrm{PM}_{10}$ and $\mathrm{PM}_{2.5}$ concentrations in other eastern cities within China were also collected at relevant environmental monitoring stations. All these data were subject to a quality control process that included a validity check. The hourly $\mathrm{PM}_{10}$ concentration was calculated only when there were greater than 45 min observations within the hour. Daily values were calculated with at least 18-h observations within the day. The monthly $\mathrm{PM}_{10}$ concentrations require at least 25 valid daily observations.

\subsection{Quantitative $\mathbf{P M}_{10}$ concentration variations}

A series of standard notations are used to quantitatively describe the duration and concentration of $\mathrm{PM}_{10}$ increments and decrements during sand-dust or anthropogenic air pollution events: $C_{\mathrm{i}}$ denotes the $\mathrm{PM}_{10}$ concentration monitoring value for each interval of $5 \mathrm{~min}$ (or each hour); i denotes the monitoring time point (i.e., $i=1,2,3, \ldots$ ); $C_{\text {imax }}$ denotes the maximum $\mathrm{PM}_{10}$ concentration value for each 5-min interval during a sand-dust weather event (or each hour) with "imax" in this case referring to the monitoring time point of maximum concentration; $\mathrm{C}_{\mathrm{n}}$ refers to a case when the concentration is less than $1000 \mu \mathrm{g} / \mathrm{m}^{3}$ (or $100 \mu \mathrm{g} / \mathrm{m}^{3}$ ) while $C_{n+1}$ is greater than $1000 \mu \mathrm{g} / \mathrm{m}^{3}$ (or 100 $\mu \mathrm{g} / \mathrm{m}^{3}$ ), $\mathrm{n}$ denotes the starting time of the contribution of sand-dust weather events (or anthropogenic air pollution event) to $\mathrm{PM}_{10}$ levels and $C_{n}$ is the concentration that corresponds to the starting time; $\mathrm{C}_{n+k}$ refers to a case when $n+k$ is greater than "imax" and $C_{n+k}$ is less than $2 C_{n}$, then $n+k$ is the end time of the contribution of sand-dust weather events (or anthropogenic air pollution event) to $\mathrm{PM}_{10}$ levels, and $C_{n+k}$ is the concentration that corresponds to the end time; $T_{\text {up }}$ denotes the $\mathrm{PM}_{10}$ concentration duration time as it increases from $C_{n}$ to $C_{\text {imax }}$ (in either minutes or hours); $T_{\text {down }}$ denotes the $\mathrm{PM}_{10}$ concentration duration time as it decreases from $C_{\text {imax }}$ to $C_{n+k}$ (in either minutes or hours); $V_{\text {up }}$ denotes the rate of $\mathrm{PM}_{10}$ concentration increase (in either minutes or hours); and $V_{\text {down }}$ denotes the rate of $\mathrm{PM}_{10}$ concentration reduction (in either minutes or hours).

The rate of either increasing or decreasing $\mathrm{PM}_{10}$ concentration can therefore be described using the following expressions:

$$
\begin{gathered}
V_{\text {up }}=\left(C_{\text {imax }}-C_{n}\right) / T_{\text {up }}, \\
V_{\text {down }}=\left(C_{\text {imax }}-C_{n+k}\right) / T_{\text {down }} .
\end{gathered}
$$

\section{Results and discussion}

\section{1 $\mathrm{PM}_{10}$ concentration variations during sand-dust weather events}

4.1.1 Annual variations in monthly average $\mathrm{PM}_{10}$ concentrations between 2004 and 2010 The results of this study reveal that $\mathrm{PM}_{10}$ concentrations across Hotan Prefecture are characterized by unusual arid climatic zone features. Figure 2 summarizes annual variations in monthly average $\mathrm{PM}_{10}$ concentrations between 2004 and 2010 that the highest values are found in the spring. The highest monthly average $\mathrm{PM}_{10}$ concentration over the course of this study is $770 \mu \mathrm{g} / \mathrm{m}^{3}$ in March followed by $768 \mu \mathrm{g} / \mathrm{m}^{3}$ in April. This pattern is different from that in eastern Chinese cities where the heaviest $\mathrm{PM}_{10}$ pollution usually occurs in winter when air contamination is due to excess emissions of local anthropogenic pollutants (Park et al., 2013; Zhao et al., 2013). In Hotan Prefecture, however, the lowest monthly average $\mathrm{PM}_{10}$ concentration recorded during sand-dust weather events was $197 \mu \mathrm{g} / \mathrm{m}^{3}$ in November. This value is higher than even the second level standard for daily average $\mathrm{PM}_{10}$ concentrations $\left(150 \mu \mathrm{g} / \mathrm{m}^{3}\right)$ within China. The number of moderately polluted (i.e., $350 \mu \mathrm{g} / \mathrm{m}^{3}<\mathrm{PM}_{10}$ concentration $\leq 420 \mu \mathrm{g} / \mathrm{m}^{3}$ ) days as well as heavily polluted ones (i.e., $\mathrm{PM}_{10}$ concentration greater than $420 \mu \mathrm{g} / \mathrm{m}^{3}$ ) in Hotan Prefecture increased by $62.1 \%$ over the period 2004-2010, much more than those in the eastern cities of China (Wang et al., 2015). 


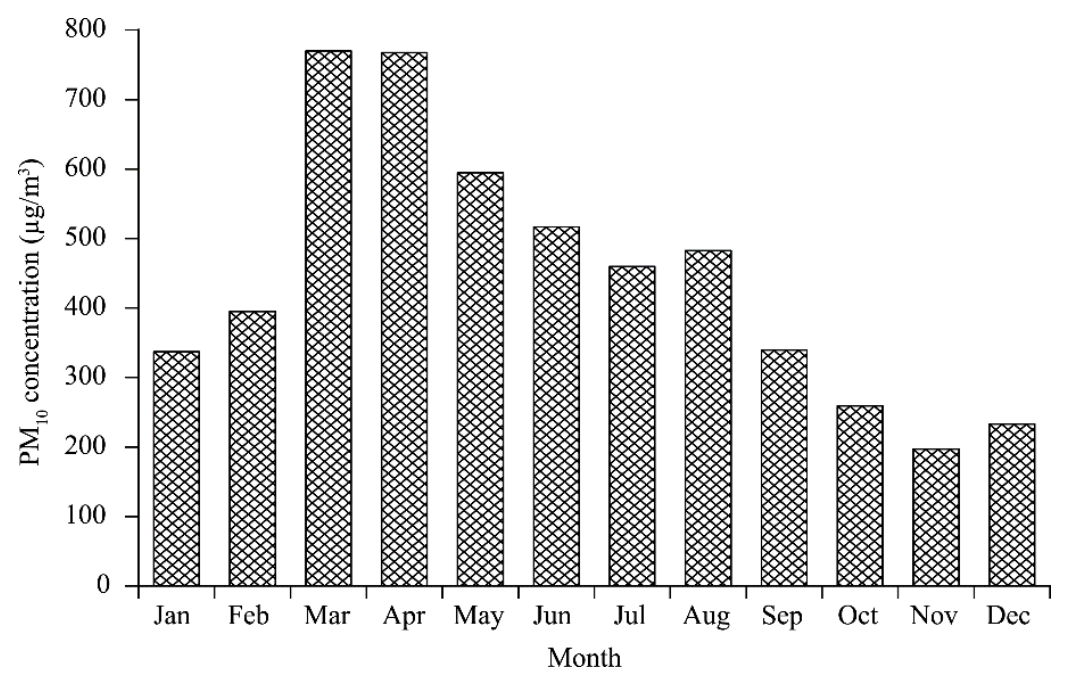

Fig. 2 Monthly average $\mathrm{PM}_{10}$ concentrations in Hotan Prefecture between 2004 and 2010

4.1.2 Occurrence and characteristics of $\mathrm{PM}_{10}$ concentrations in sand-dust weather events Three kinds of sand-dust weather events are typically seen within Hotan Prefecture, i.e., dust storms as well as blowing and floating dust. We calculated monthly average days of occurrence for these three weather events for each month to compare the characteristics of $\mathrm{PM}_{10}$ concentrations in the three sand-dust patterns (Table 1). These data show that the maximum monthly average day of occurrence in the case of floating dust events is in March (14.4 d), followed by April (12.9 d); floating dust occurs throughout the year on up to 96.4 days, while blowing dust and storms occur on only about 28 days overall and almost always within the spring-summer period. The ratio between floating dust days and total sand-dust weather days reaches as high as 0.89 in March and 0.82 in April, and remains greater than 0.60 throughout the spring-summer period. The $\mathrm{PM}_{10}$ concentration level across Hotan Prefecture is subjected to the continuous influence of floating dust rather than storms and blowing dust; this means that floating dust events make the largest contributions to $\mathrm{PM}_{10}$ (or $\mathrm{PM}_{2.5}$ ) concentration across this region.

Table 1 Monthly mean days of occurrence for the three distinct types of sand-dust weather events in Hotan Prefecture between 2004 and 2010

\begin{tabular}{|c|c|c|c|c|c|c|c|c|c|c|c|c|c|}
\hline \multirow{2}{*}{ Weather event } & \multicolumn{13}{|c|}{ Number of days (d) } \\
\hline & Jan & Feb & Mar & Apr & May & Jun & Jul & Aug & Sep & Oct & Nov & Dec & Annual \\
\hline Floating dust & 3.1 & 6.1 & 14.4 & 12.9 & 12.6 & 11.0 & 8.7 & 11.3 & 7.8 & 4.5 & 1.7 & 2.3 & 96.4 \\
\hline Blowing dust & 0.0 & 0.4 & 1.3 & 1.4 & 3.9 & 4.7 & 3.3 & 2.3 & 1.3 & 0.3 & 0.0 & 0.3 & 19.2 \\
\hline Dust storm & 0.0 & 0.0 & 0.4 & 1.4 & 2.0 & 2.6 & 1.0 & 1.0 & 0.2 & 0.3 & 0.0 & 0.0 & 8.9 \\
\hline
\end{tabular}

The data presented in Figure 3 reveal clear differences in monthly mean $\mathrm{PM}_{10}$ concentrations for three types of sand-dust weather events between March and August. Values are much higher in both March and April than in other months; in these months, mean $\mathrm{PM}_{10}$ concentrations due to floating dust are 1143 and $1198 \mu \mathrm{g} / \mathrm{m}^{3}$, respectively, while mean values due to dust storms are 1120 and $1104 \mu \mathrm{g} / \mathrm{m}^{3}$, respectively. Similarly, mean values due to blowing dust in these months are 950 and $1037 \mu \mathrm{g} / \mathrm{m}^{3}$, respectively. Data also reveal that monthly average $\mathrm{PM}_{10}$ concentrations in March and April due to floating dust events are higher than those due to storms and blowing dust.

The monthly maximum $\mathrm{PM}_{10}$ concentrations (not illustrated here) during dust storm events between March and August range from 4260 to $6480 \mu \mathrm{g} / \mathrm{m}^{3}$, while those during blowing dust events range from 1674 to $3839 \mu \mathrm{g} / \mathrm{m}^{3}$, and those during floating dust events range from 1461 to 2129 $\mu \mathrm{g} / \mathrm{m}^{3}$. These results are consistent with previous studies (Wan et al., 2004; Liu et al., 2008), which show that the $\mathrm{PM}_{10}$ concentration caused by floating dust weather events remains at a high-level over long periods (as in the three cases discussed below) and that the monthly mean days of 
occurrence of floating dust events is also the highest in these cases (Table 1). It is therefore clear that the total contribution from floating dust events to overall $\mathrm{PM}_{10}$ concentration is very high within Hotan Prefecture.

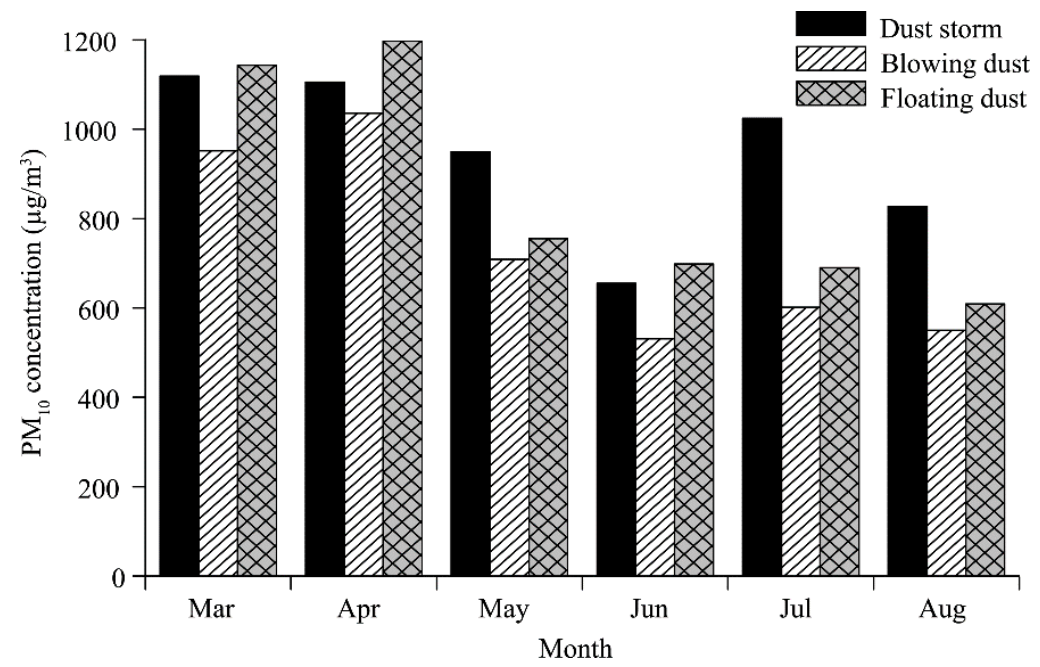

Fig. 3 Daily mean $\mathrm{PM}_{10}$ concentrations in Hotan Prefecture from March to August between 2004 and 2010

Hourly variations in mean $\mathrm{PM}_{10}$ concentration during the three kinds of sand-dust weather events are also analyzed to understand their differences. Three cases which represent variations in hourly mean $\mathrm{PM}_{10}$ concentration during these events are presented in Figure 4 . The hourly mean $\mathrm{PM}_{10}$ concentrations of three types all significantly increase during the first few hours of the events. The maximum hourly mean $\mathrm{PM}_{10}$ concentration of the three sand-dust patterns conforms to the sequence such that dust storms are greater than blowing dust, which is greater than floating dust (i.e., $5810,4485,3614 \mu \mathrm{g} / \mathrm{m}^{3}$, respectively). The intensities of these sand-dust weather events are defined by their level of visibility and wind speed, and again also conform to the sequence such that dust storms are more significant than blowing dust which is more significant than the floating dust. Dust storms and blowing dust lead to increases in $\mathrm{PM}_{10}$ concentrations initially then the $\mathrm{PM}_{10}$ levels decreased (as is also seen in the other cases; not illustrated). These high concentrations last only about $3 \mathrm{~h}$. However, $\mathrm{PM}_{10}$ levels may remain high for many hours (even days) in the case of floating dust events subsequent concentrations being first reached the highest level (as is also seen in the other cases, not illustrated). This means that floating dust events made a greater

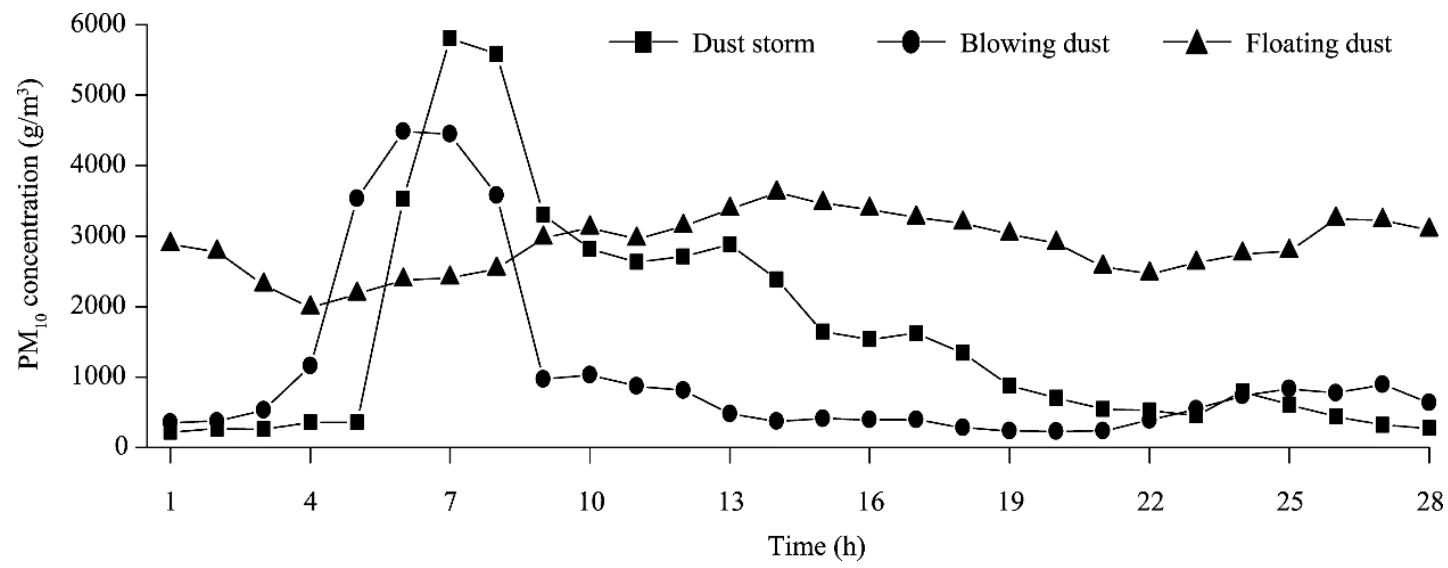

Fig. 4 Hourly mean PM10 concentrations. The dust storm occurred between 05:00 on 27 April 2015 and 08:00 on 28 April 2015; the blowing dust occurred between 11:00 on 16 April 2015 and 15:00 on 17 April 2015; and the floating dust occurred between 13:00 on 2 April 2015 and 16:00 on 3 April 2015. 
contribution overall to monthly mean $\mathrm{PM}_{10}$ concentration than either of the other two sand-dust weather events because of a long-lasting higher pollutant concentration. Note that the proportion of extremely fine dust with particle sizes between 0.250 and $0.063 \mu \mathrm{m}$ from floating dust around the edge of the Taklimakan Desert is greater than $85 \%$ (Gao and Jiang, 2002). Smaller-sized particulate matter tends to be easily lifted off from the ground and remains in the air for a longer time; these materials are also more harmful to the local air environment and the health of residents compared to either storm events or blowing dust event.

The temporal variations of hourly mean $\mathrm{PM}_{2.5}$ concentrations are similar to $\mathrm{PM}_{10}$ concentrations during the three kinds of sand-dust weather events (Fig. 5). At the beginning of the dust storm, $\mathrm{PM}_{2.5}$ concentration increases quickly to a maximum of $1922 \mu \mathrm{g} / \mathrm{m}^{3}$, while hourly mean $\mathrm{PM}_{2.5}$ concentration variations appear to decline in a fluctuating manner during the dust storm. Concentrations of $\mathrm{PM}_{2.5}$ are then maintained and steadily reduced in the aftermath of the storm, while variations in hourly mean $\mathrm{PM}_{2.5}$ concentrations are similar to variations in $\mathrm{PM}_{10}$ concentrations during both blowing dust and floating dust events. Figure 5 shows that $\mathrm{PM}_{2.5}$ concentration maxima are significantly lower than $\mathrm{PM}_{10}$ concentration, just 1110 and $511 \mu \mathrm{g} / \mathrm{m}^{3}$, respectively. As particles in these cases are smaller and float more easily in the air (as is the case on other gaseous pollutants), $\mathrm{PM}_{2.5}$ pollution tends to worsen the horizontal air visibility. These particles also invade the human respiratory tract and compromise health.

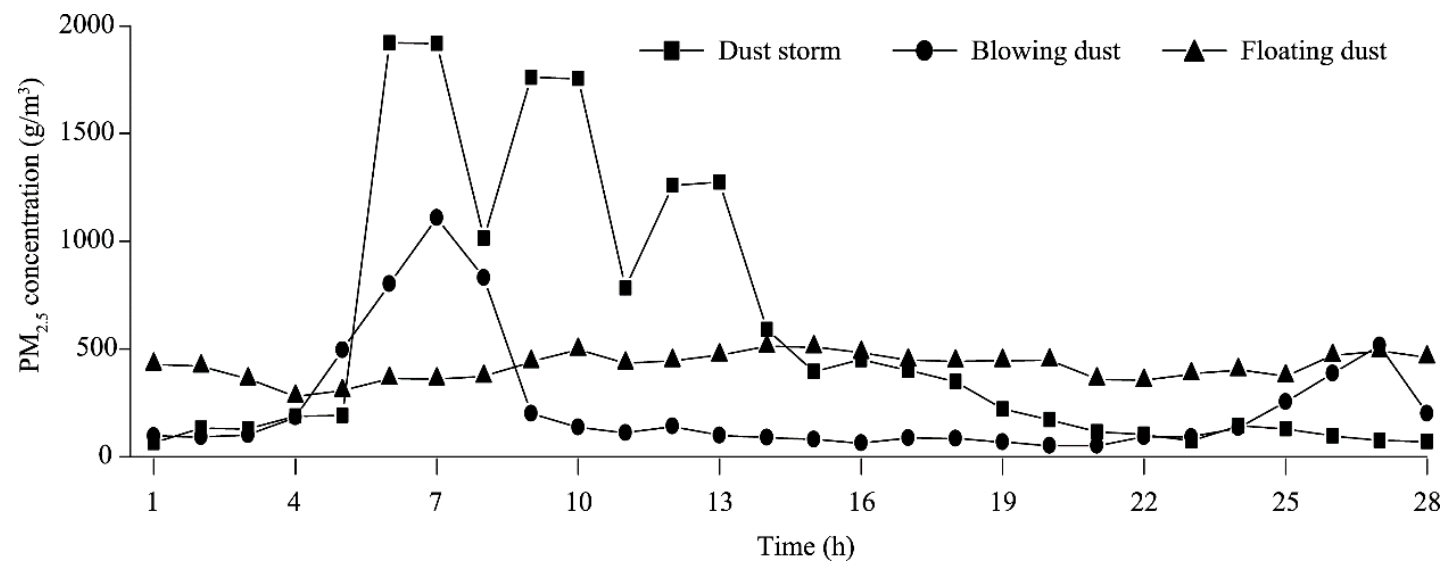

Fig. 5 Hourly mean $\mathrm{PM}_{2.5}$ concentrations (the occurred time of the weather events were same as in Figure 4)

\subsection{Variations in hourly mean $\mathrm{PM}_{10}$ concentrations in Hotan Prefecture during dust storm events compared with anthropogenic pollution events}

Dust storms are the most intense kinds of sand-dust weather events. These storms result in very heavy particulate matter pollution as a large amount of sand-dust is blowing into the air. More than 20 dust storm events occurred in Hotan Prefecture over the period 2004-2010 due to strong cold air invasions. We selected one of the dust storm events occurred on 8 May 2007 and the variations in hourly mean $\mathrm{PM}_{10}$ concentrations during this event are summarized in Figure 6.

Before the onset of the dust storm shown in Figure 6, the hourly mean $\mathrm{PM}_{10}$ concentration in Hotan was $1117 \mu \mathrm{g} / \mathrm{m}^{3}$. Once this storm arrived in Hotan Prefecture, the $\mathrm{PM}_{10}$ concentration sharply increased over the first $9 \mathrm{~h}$, reaching a maximum of $8942 \mu \mathrm{g} / \mathrm{m}^{3}$, more than eight times the level prior to the event. At the same time, horizontal visibility in the air decreased below $300 \mathrm{~m}$ in this region while over the next $26 \mathrm{~h}$ (after reaching maximum concentration), the $\mathrm{PM}_{10}$ concentration within the prefecture slowly decreased to $1097 \mu \mathrm{g} / \mathrm{m}^{3}$. The variation that characterizes this process can be summarized as "sharp increase followed by slow decrease". This contrasts with the process of heavy air pollution that was evaluated in Beijing during the winter (green curve) as the result of excessive emissions from local anthropogenic pollutants and adverse atmospheric diffusion conditions (Cheng et al., 2015). In Beijing case, variation in hourly mean $\mathrm{PM}_{10}$ concentrations comprised a gradual accumulation for $34 \mathrm{~h}$; a slow increase from $110 \mu \mathrm{g} / \mathrm{m}^{3}$ to a maximum of 198 $\mu \mathrm{g} / \mathrm{m}^{3}$. A high $\mathrm{PM}_{10}$ concentration lasted for only about $4 \mathrm{~h}$ in this case then weather conditions 
favoring the quick diffusion of pollutants reduced the $\mathrm{PM}_{10}$ concentration to $56 \mu \mathrm{g} / \mathrm{m}^{3}$ within just 2 $\mathrm{h}$. The variation that characterizes this process can be summarized as "slow increase followed by sharp decrease".

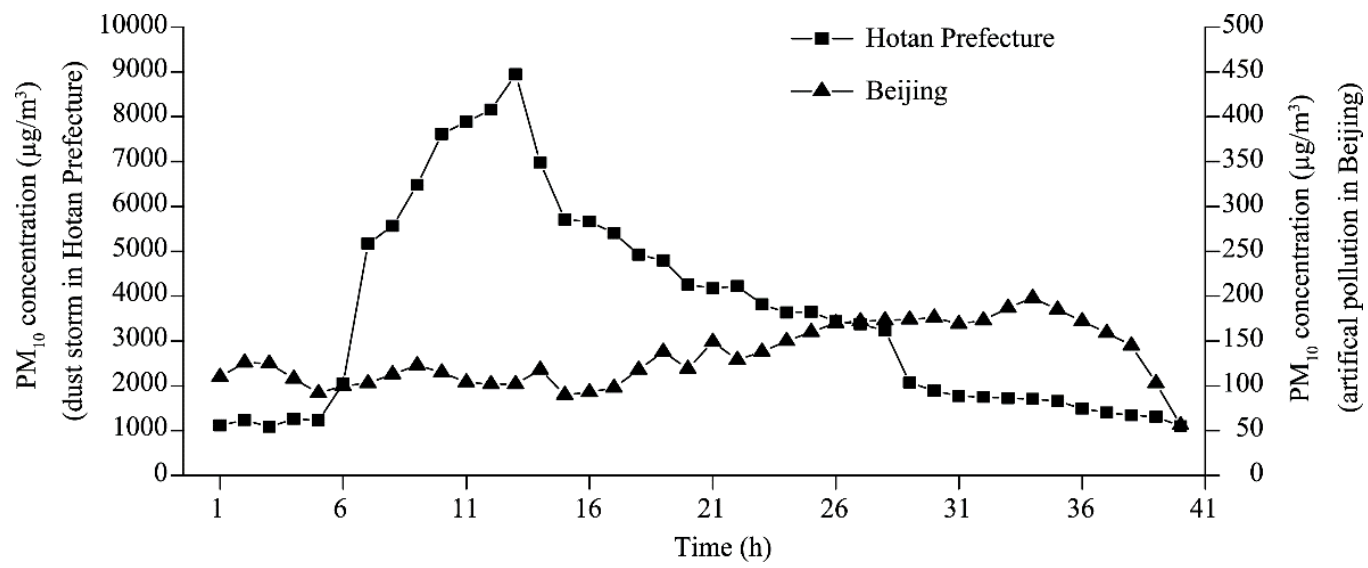

Fig. 6 Hourly mean $\mathrm{PM}_{10}$ concentrations during the dust storm occurred in Hotan Prefecture between 02:00 on 8 May 2007 and 17:00 on 9 May 2007 and the anthropogenic pollution events occurred in Beijing between 03:00 on 18 February 2015 and 18:00 on 19 February 2015

The characteristics of $\mathrm{PM}_{10}$ concentration variation from 20 cases of strong dust storm events that occurred between 2004 and 2010 are summarized in Table 2 to confirm whether, or not, this kind of variation pattern (i.e., "sharp increase followed by slow decrease") in hourly mean $\mathrm{PM}_{10}$

Table 2 Variation in $\mathrm{PM}_{10}$ concentration rate and durations of increase or decrease from the 20 cases of dust storm during 2004-2010

\begin{tabular}{|c|c|c|c|c|}
\hline \multirow{2}{*}{ Date } & $T_{\text {up }}$ & $V_{\text {up }}$ & $T_{\text {down }}$ & $V_{\text {down }}$ \\
\hline & $(\min )$ & $\left(\mu \mathrm{g} /\left(\mathrm{m}^{3} \cdot \min \right)\right)$ & $(\min )$ & $\left(\mu \mathrm{g} /\left(\mathrm{m}^{3} \cdot \min \right)\right)$ \\
\hline 23 Apr 2004 & 164 & 55.1 & 840 & 9.9 \\
\hline 21 May 2004 & 95 & 98.8 & 435 & 21.0 \\
\hline 8 May 2005 & 110 & 72.7 & 140 & 57.2 \\
\hline 19 Jul 2006 & 40 & 176.9 & 185 & 33.2 \\
\hline 23 Aug 2006 & 30 & 299.6 & 350 & 25.4 \\
\hline 8 May 2007 & 90 & 102.2 & 610 & 15.4 \\
\hline 6 Jun 2007 & 25 & 369.2 & 170 & 50.4 \\
\hline 8 Jul 2007 & 80 & 121.2 & 385 & 24.8 \\
\hline 19 Mar 2008 & 50 & 176.2 & 150 & 55.3 \\
\hline 5 May 2008 & 80 & 107.4 & 640 & 12.4 \\
\hline 23 May 2008 & 50 & 185.6 & 175 & 50.9 \\
\hline 28 Jun 2008 & 35 & 227.1 & 60 & 127.2 \\
\hline $11 \mathrm{Jul} 2008$ & 25 & 314.4 & 125 & 54.2 \\
\hline 19 Mar 2009 & 50 & 169.8 & 240 & 33.1 \\
\hline 16 Apr 2009 & 75 & 114.4 & 1262 & 5.8 \\
\hline 25 May 2009 & 60 & 113.3 & 215 & 28.5 \\
\hline 2 Jun 2009 & 40 & 146.2 & 115 & 46.0 \\
\hline 5 Jul 2009 & 30 & 183.0 & 30 & 120.1 \\
\hline 2 Aug 2009 & 45 & 128.1 & 175 & 31.2 \\
\hline 12 Mar 2010 & 85 & 107.6 & 260 & 33.6 \\
\hline Average & 63 & 163.4 & 328 & 41.8 \\
\hline
\end{tabular}

Note: The meaning of $T_{\text {up }}, V_{\text {up }}, T_{\text {down }}$, and $V_{\text {down }}$ refer to Section 3.2. 
concentrations in Hotan Prefecture during dust storm events is common. To further address this process, increase and decrease rates as well as durations for $\mathrm{PM}_{10}$ concentration are computed statistically. During these dust storm processes, variations in $\mathrm{PM}_{10}$ concentrations are characterized by a significant increase within a short period from the onset of dust storms followed by a remarkably slower decrease over a relatively long time while a dust storm start to weaken. The average time of increase of $\mathrm{PM}_{10}$ concentration is $63 \mathrm{~min}$ over the 20 cases assessed in this study. The shortest lasting time in which $\mathrm{PM}_{10}$ concentration increased to the maximum was $25 \mathrm{~min}$; this yielded a mean $\mathrm{PM}_{10}$ concentration rate of increase rate of $163.4 \mu \mathrm{g} /\left(\mathrm{m}^{3} \cdot \mathrm{min}\right)$. In contrast, the longest time duration during which the $\mathrm{PM}_{10}$ concentration decreased to the minimum was 1262 min, while the average time reduction over the 20 dust storm cases was 328 min, over five times the length of the $\mathrm{PM}_{10}$ concentration increase. Similarly, the mean decrease rate of $\mathrm{PM}_{10}$ concentration was $41.8 \mu \mathrm{g} /\left(\mathrm{m}^{3} \cdot \mathrm{min}\right)$, one quarter the mean increase rate. Statistics from $20 \mathrm{dust}$ storms in Hotan Prefecture are consistent with a "sharp increase followed by a slow decrease". Previous research by Yang et al. (2016) suggested that variations in dust events are mainly affected by strong winds and daily temperatures with correlation coefficients of 0.46 and -0.41 for dust events respectively across the whole Taklimakan Desert. This correlation analysis indicates that a strong wind is the dominant factor that results in the formation of sand-dust storms. At the same time, temperature is also negatively correlated with the number of dust storm days in the Taklimakan Desert (Xiao et al., 2008) and is indicative of the influence of cold air activity on these events.

The characteristics of $\mathrm{PM}_{10}$ concentration variation from the five heavy anthropogenic air pollution events that occurred in five eastern Chinese cities between 2004 and 2016 are listed in Table 3 to demonstrate whether, or not, a "slow increase followed by a sharp decrease" during anthropogenic heavy air pollution events can also be considered universal. These data encapsulate the increase and decrease rates of $\mathrm{PM}_{10}$ concentrations and their duration for each anthropogenic heavy air pollution process and so are subject to statistically analyses. These results show that during these five heavy anthropogenic air pollution events, variations in $\mathrm{PM}_{10}$ concentrations exhibit significant increases over long time periods from the onset of the pollution process. A remarkably quick decrease also occurred within a relatively short time when the atmospheric diffusion condition improved. The longest time duration, over which the $\mathrm{PM}_{10}$ concentration increased to a maximum was $67 \mathrm{~h}$, while the average duration over which this concentration increased throughout the five test cases evaluated here is $45 \mathrm{~h}$. This translates to a mean $\mathrm{PM}_{10}$ concentration increase rate of $15.4 \mu \mathrm{g} /\left(\mathrm{m}^{3} \cdot \mathrm{h}\right)$; the shortest duration over which $\mathrm{PM}_{10}$ concentration decreases to a minimum is $10 \mathrm{~h}$, while the average duration in the five anthropogenic air pollution cases is $12 \mathrm{~h}$, almost one quarter of the mean $\mathrm{PM}_{10}$ concentration increase time. This translates to a mean $\mathrm{PM}_{10}$ concentration decrease rate of $58.6 \mu \mathrm{g} /\left(\mathrm{m}^{3} \cdot \mathrm{h}\right)$, nearly four times the corresponding increase rate. Thus, the five cases discussed here within the five eastern Chinese cities are consistent with the "slow increase followed by a sharp decrease" as previously noted.

Table 3 Variation in $\mathrm{PM}_{10}$ concentration rates and lasting time of increase or decrease from five cases of anthropogenic heavy air pollution events in the five eastern cities of China between 2004 and 2016

\begin{tabular}{cccccc}
\hline \multirow{2}{*}{ Date } & City & $T_{\text {up }}$ & $V_{\text {up }}$ & $T_{\text {down }}$ & $V_{\text {down }}$ \\
\cline { 3 - 6 } & & $(\mathrm{h})$ & $\left(\mu \mathrm{g} /\left(\mathrm{m}^{3} \cdot \mathrm{h}\right)\right)$ & $(\mathrm{h})$ & $\left(\mu \mathrm{g} /\left(\mathrm{m}^{3} \cdot \mathrm{h}\right)\right)$ \\
\hline 20 Feb 2015 & Beijing & 30 & 19.3 & 10 & 61.2 \\
7 Dec 2015 & Baoding & 67 & 9.9 & 13 & 61.8 \\
7 Dec 2015 & Shijiazhuang & 66 & 7.3 & 15 & 30.1 \\
31 Dec 2015 & Tianjin & 52 & 12.6 & 12 & 56.3 \\
2 Jan 2016 & Jinan & 22 & 21.9 & 10 & 54.8 \\
Average & & 45 & 15.4 & 12 & 58.6 \\
\hline
\end{tabular}

The characteristics of the $\mathrm{PM}_{2.5}$ to $\mathrm{PM}_{10}$ concentration ratio between the air pollution events discussed are different between the case of sand-dust weather events and anthropogenic heavy air pollution events (Fig. 7). A higher ratio is seen in the case of anthropogenic heavy air pollution 
events. The ratio remains higher in intense air pollution events because of the effects of urbanization and anthropogenic influences. $\mathrm{PM}_{2.5}$ is mostly emitted as a result of incomplete combustion of biomass burning and fossil fuel as well as via regenerated air pollutants. In these circumstances, the ratio is always greater than 0.5 . The average ratio in this analysis is 0.8 with a range of 0.6-1.0. Lower ratios for the $\mathrm{PM}_{2.5} / \mathrm{PM}_{10}$ concentration are discovered for the three kinds of sand-dust weather events. During both blowing events and floating dust events, $\mathrm{PM}_{2.5} / \mathrm{PM}_{10}$ concentration ratios are less than 0.3 , and these values remain low throughout relative to those seen in anthropogenic air pollution events. Although the $\mathrm{PM}_{2.5}$ concentration increases very rapidly at the start of the dust storm to a ratio close to 0.5 , it nevertheless remains lower than those seen in intense anthropogenic air pollution events.

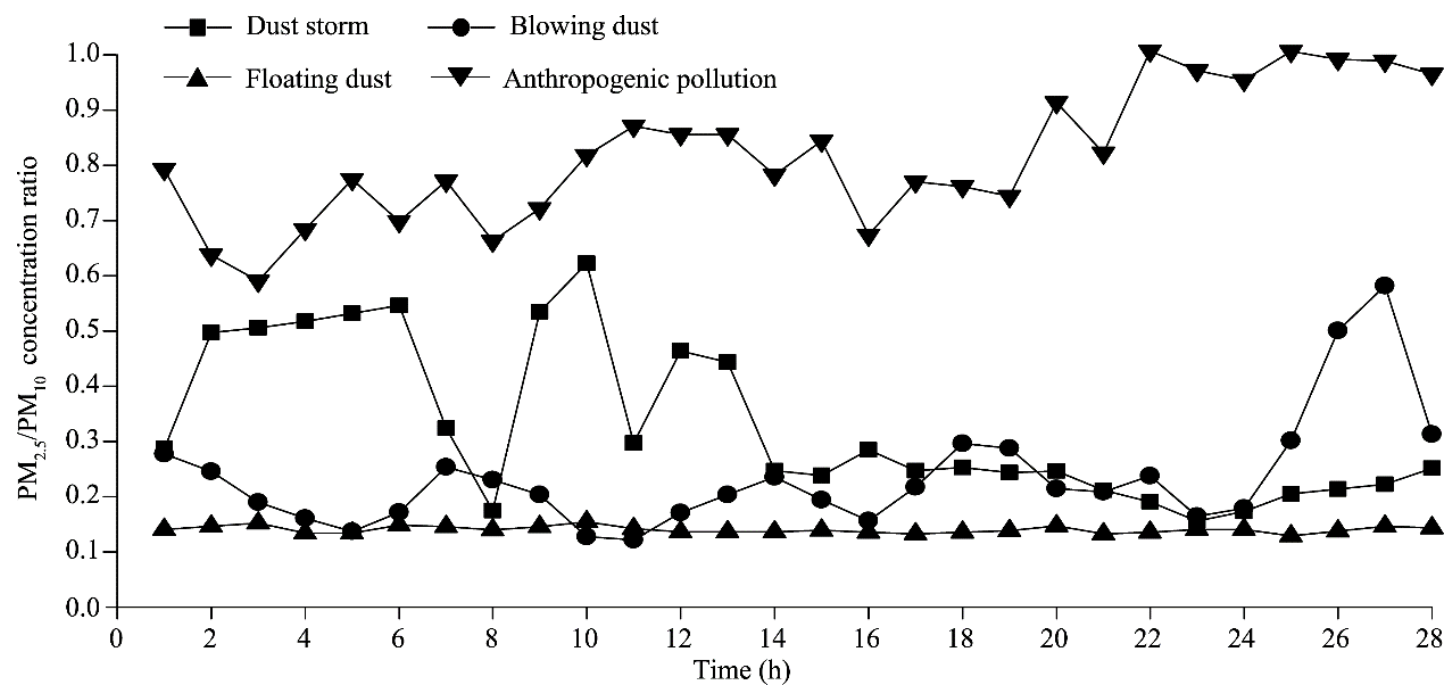

Fig. 7 Hourly $\mathrm{PM}_{2.5} / \mathrm{PM}_{10}$ concentration ratio during different pollution events. The dust storm occurred between 05:00 on 27 April 2015 and 08:00 on 28 April 2015; the blowing dust event occurred between 11:00 on 16 April 2015 and 15:00 on 17 April 2015; the floating dust event occurred from 13:00 on 2 April 2015 to 16:00 on 3 April 2015; and the anthropogenic pollution event occurred in Beijing between 03:00 on 18 February 2015 and 18:00 on 19 February 2015.

\subsection{Influence of sand-dust weather events on the gaseous air pollutant concentrations}

It is a common knowledge that the major gaseous pollutants in the atmosphere include $\mathrm{SO}_{2}, \mathrm{CO}$, nitrogen oxides $\left(\mathrm{NO}_{\mathrm{x}}\right)$, and $\mathrm{O}_{3}$. The primary sources of these pollutants include the combustion of fossil fuels in power plants, various industrial processes, as well as motor vehicles and equipment. These pollutants all enter the environment and are harmful to human health, even though their concentrations are far lower than those of corresponding particulate materials (Dickhut et al., 2000).

Thus, the impacts of three kinds of sand-dust weather events are analyzed to obtain more useful information regarding the influence of different kinds of sand-dust weather events on the characteristics of gaseous air pollutant variation within Hotan Prefecture. We assess the concentrations of gaseous pollutants using additional data for $\mathrm{SO}_{2}, \mathrm{NO}_{2}, \mathrm{CO}$, and $\mathrm{O}_{3}$ collected at the beginning of 2015. Variations in hourly mean gaseous pollutant concentrations are summarized in Figures 8-10, including $\mathrm{SO}_{2}, \mathrm{CO}, \mathrm{NO}_{2}$, and $\mathrm{O}_{3}$.

Figure 8 shows that hourly mean variations in gaseous pollutant concentrations $\left(\mathrm{SO}_{2}, \mathrm{CO}, \mathrm{NO}_{2}\right.$, and $\mathrm{O}_{3}$ ) during the three types of sand-dust weather events in Hotan Prefecture differed greatly from $\mathrm{PM}_{10}$ (or $\mathrm{PM}_{2.5}$ ) concentrations (Figs. 8-10). This indicates that the influence of different kinds of sand-dust weather events on the concentration of gaseous air pollutants varies compared to particulate matter pollution. Hourly variations in $\mathrm{SO}_{2}$ concentration due to the three sand-dust event types are presented in Figure 8. 


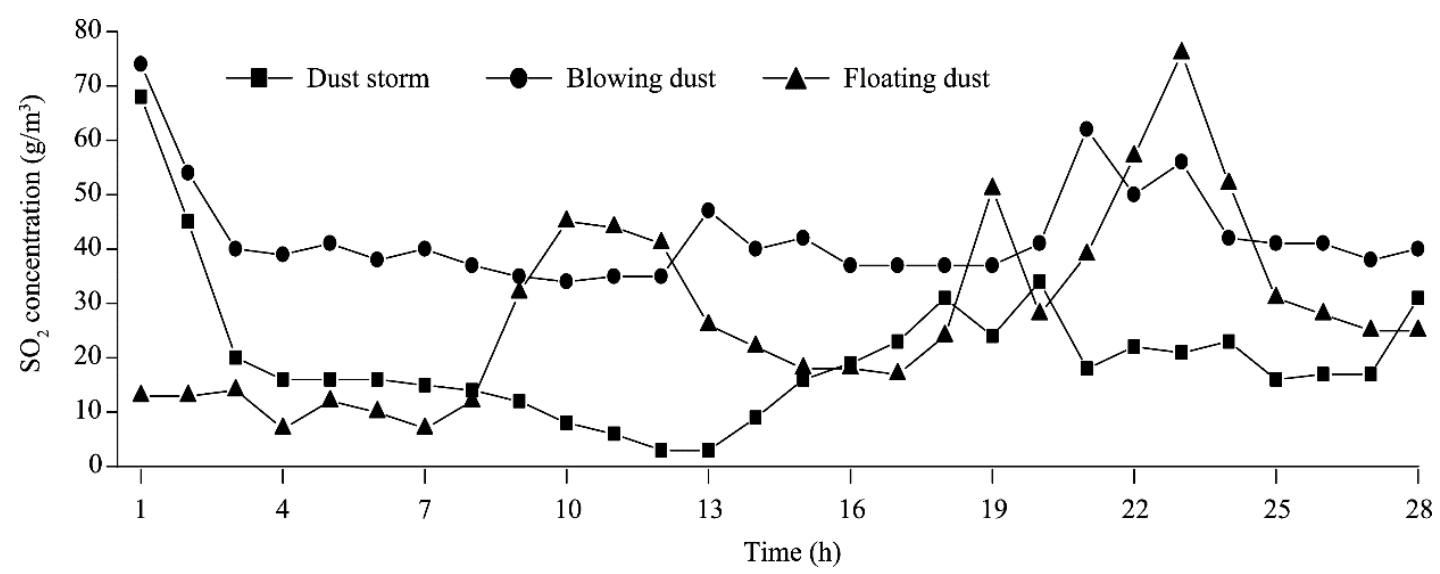

Fig. 8 Variation in hourly mean $\mathrm{SO}_{2}$ concentrations during the three types of sand-dust weather events in Hotan Prefecture

It is clear that hourly mean $\mathrm{SO}_{2}$ concentration quickly decreases initially then falling more gradually during both dust storms and blowing dust events because of rapidly increasing wind velocity and the formation of favorable atmospheric diffusion conditions subsequent onset. These data also clearly show that dust storms and blowing dust events might remove $\mathrm{SO}_{2}$ from the local air owing to favorable atmospheric diffusion. It is noteworthy that $\mathrm{SO}_{2}$ concentrations during blowing dust events remain at a higher level than the cases of dust storms. These concentrations have also generally rise in a fluctuating manner during floating dust storms while CO concentrations remained significantly higher during these events than the case during either dust storm and blowing dust periods (Fig. 9). These interesting phenomena will require further study.

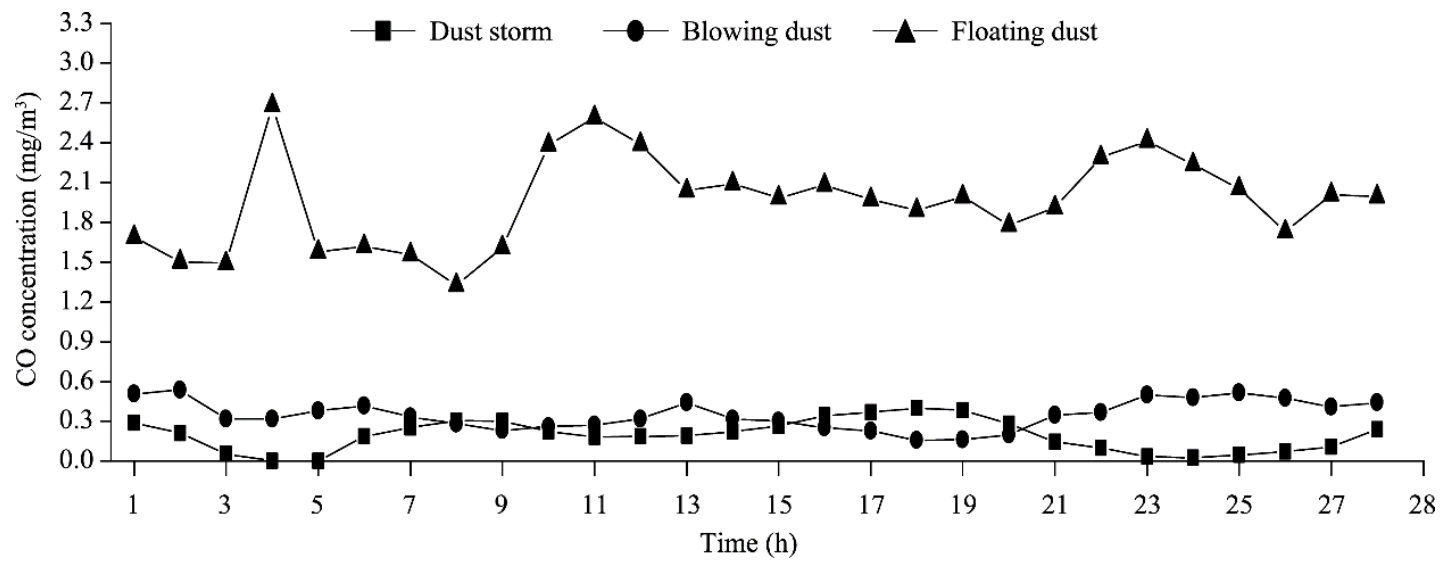

Fig. 9 Variation in hourly mean CO concentrations during the three types of sand-dust weather events in Hotan Prefecture

A range of other gaseous pollutants are also analyzed, including inter-hourly variations in $\mathrm{NO}_{2}$ and $\mathrm{O}_{3}$ concentrations during the three types of sand-dust weather events (Fig. 10). These gases form during primary emission or secondary transformation and can also interconvert. This means that inter-hourly variations in the concentration of $\mathrm{NO}_{2}$ and $\mathrm{O}_{3}$ represent the intensity of secondary transformation and indicate the existence of secondary resultants. Data also show that $\mathrm{NO}_{2}$ concentration remains the lowest in all the six air pollutants as well as during dust storm periods compared to the other two kinds of sand-dust weather events. This gas also occurs at a higher concentration in the floating dust compared to the blowing form; similarly, the $\mathrm{O}_{3}$ concentration that occurs during the floating dust period is also lower than in either storm or blowing phases. Some researchers have even suggested a cause for these $\mathrm{O}_{3}$ concentration variations. Aerosol direct effects (ADE) (including the scattering and absorption of incoming solar radiation) reduce the 
proportion of radiation that reaches the ground and resultant photolytic attenuation decreases the formation of this gas in polluted areas. Evidence also suggests that ADE-associated cooling suppresses atmospheric ventilation, thereby enhancing surface-level $\mathrm{O}_{3}$ (Xing et al., 2017).
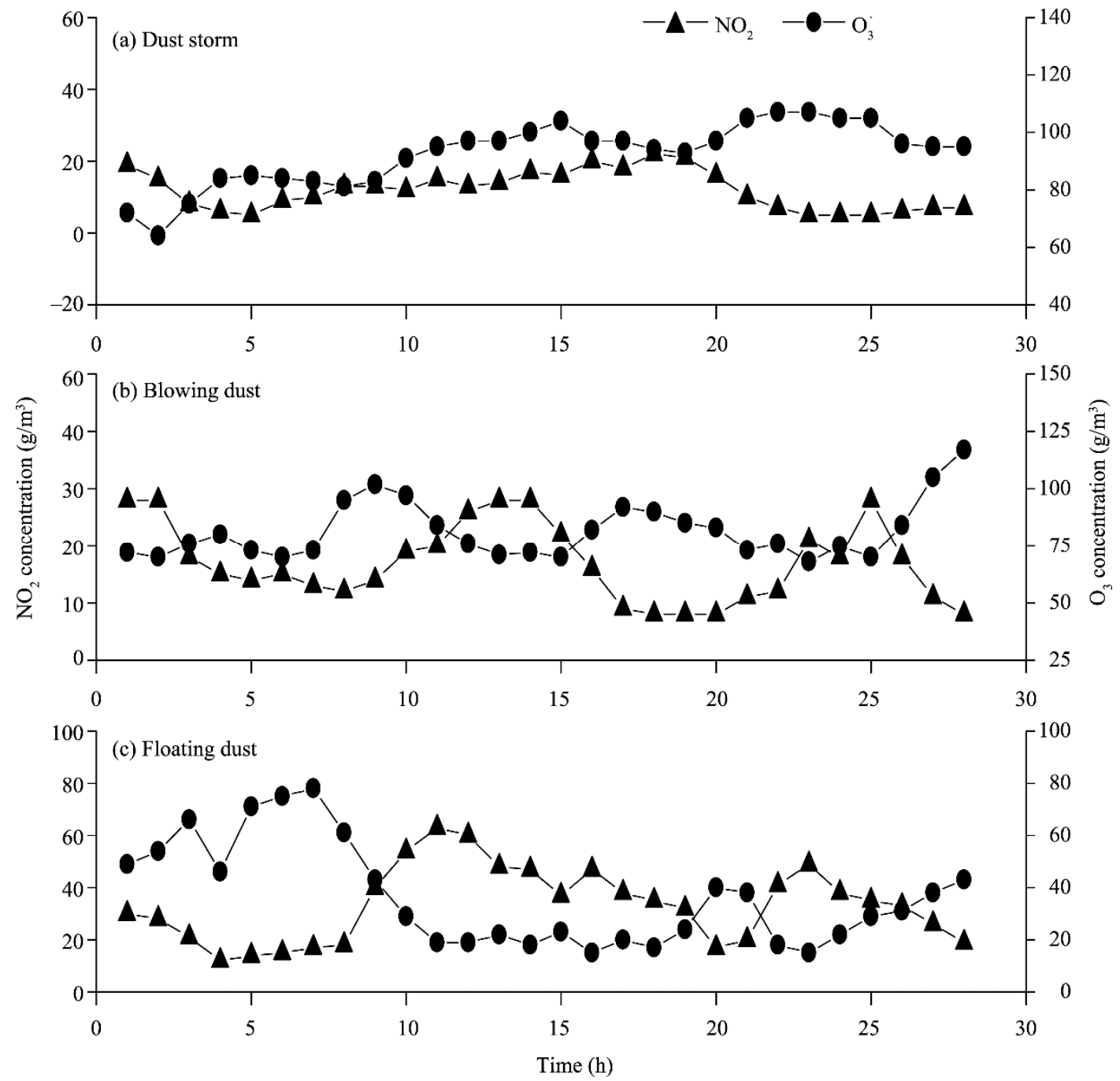

Fig. 10 Variation in hourly mean $\mathrm{NO}_{2}$ and $\mathrm{O}_{3}$ concentrations during the three types of sand-dust weather events in Hotan Prefecture

The ratios of hourly averaged concentration (i.e., the averaged pollutant concentration of sanddust weather events divided by the averaged pollutant concentration of the same variety during the corresponding time period under clear sky conditions) of all events are calculated for the area over Hotan Prefecture between 1 February 2015 and 31 July 2015 (Table 4) to examine whether, or not, these characteristics describing the variation in gaseous pollutant concentrations during the three types of sand-dust weather events are common. The concentrations of particulate matter that derive from sand-dust weather events are greater than that of the cases under clear sky conditions. Indeed, of the weather events considered here, dust storms exhibit the highest particulate matter concentration values; $\mathrm{PM}_{10}$ and $\mathrm{PM}_{2.5}$ concentrations in this case are twelve times and ten times higher than under clear sky conditions, respectively. Similarly, $\mathrm{PM}_{10}$ and $\mathrm{PM}_{2.5}$ concentrations are three to four times and two to three times higher than under clear sky conditions during blowing and floating dust events, respectively. During sand-dust weather events, the concentrations of gaseous pollutants are also lower than under clear sky conditions; this is especially the case in dust storms, events characterized by the lowest concentrations of gaseous pollutants. These kinds of 
storms actually effectively remove and rapidly diffuse gaseous pollutants. Finally, it is noteworthy that this study does reveal a number of discrepancies in terms of the impacts of sand-dust weather events on gaseous pollutant; concentrations of $\mathrm{SO}_{2}$ and $\mathrm{NO}_{2}$ are lower in the three sand-dust patterns than under clear sky conditions, while $\mathrm{CO}$ levels are lower in dust storms and blowing dust events but are higher in floating dust. Concentrations of $\mathrm{O}_{3}$ are lower in floating and blowing dust events and higher in dust storms.

Table 4 Ratios of pollutant concentrations during sand-dust weather events compared to those seen under clear sky conditions

\begin{tabular}{lrrrrrc}
\hline Sand-dust event & $\mathrm{PM}_{10}$ & $\mathrm{PM}_{2.5}$ & $\mathrm{SO}_{2}$ & $\mathrm{NO}_{2}$ & $\mathrm{CO}$ & $\mathrm{O}_{3}$ \\
\hline Dust storm & 12.23 & 10.49 & 0.74 & 0.40 & 0.36 & 1.24 \\
Blowing dust & 4.54 & 3.99 & 0.84 & 1.00 & 0.70 & 0.81 \\
Floating dust & 3.27 & 2.48 & 0.75 & 0.90 & 1.06 & 0.92 \\
\hline
\end{tabular}

\section{Conclusions}

Sand-dust weather events in Hotan Prefecture can occur during any month of a year, but are especially frequent in the spring. March and April are characterized by a significantly higher number of such events compared to the other months, while floating dust events make a significant contribution to high-level $\mathrm{PM}_{10}$ concentrations. The results show that hourly mean $\mathrm{PM}_{10}$ concentrations increase quickly at the beginning of the three kinds of sand-dust weather events, especially during dust storms, then decreasing slowly during the dissipation of these weather events.

Rates of variations in $\mathrm{PM}_{10}$ concentration as well as duration in dust storm events are computed statistically based on 20 strong dust storms occurred in 2004-2010. Case studies as well as statistics for particulate matter pollution processes from the 20 dust storm events reveal that the hourly mean $\mathrm{PM}_{10}$ concentration variation can be characterized as "a sharp increase followed by a slow decrease". On the contrary, it has been found that "a slow increase followed a sharp decrease" in $\mathrm{PM}_{10}$ concentration variation during heavy air pollution processes happened in eastern Chinese cities due to excess local anthropogenic pollutant emissions and adverse atmospheric diffusion conditions. In addition, the heavy particulate matter pollution caused by sand-dust events in Hotan Prefecture mainly occur in March and April and this differs from the heavy anthropogenic pollution processes that usually occur in winter in eastern Chinese cities.

During both blowing and floating dust events, $\mathrm{PM}_{10}$ (or $\mathrm{PM}_{2.5}$ ) concentrations are higher than those under clear sky conditions, while the $\mathrm{SO}_{2}$ concentration gradually decreases during dust storms, which provide favorable atmospheric conditions for diffusion. It is found that changes in $\mathrm{O}_{3}$ and $\mathrm{NO}_{2}$ concentrations conform to the opposite trend.

It is noteworthy that the three types of sand-dust weather events considered here all have significant impacts on local air quality in Hotan Prefecture. It is clear that floating dust events make the greatest contribution to $\mathrm{PM}_{10}$ (or $\mathrm{PM}_{2.5}$ ) concentration. This form of particulate matter is most harmful to local air quality and the health of residents due to the longer-lasting effects of higher pollutant concentrations and a larger amount of fine material compared to the other two types of dust storm weather events. Additional research on the influence of floating dust on the health of the local people will therefore be important. It is also necessary to emphasize research that addresses the causes of differences between the influences of the different types of sand-dust weather events on both gaseous and particulate matter.

\section{Acknowledgements}

The research was supported by the National Natural Science Foundation of China (91644226), the National Key Research Project of China (2016YFA0602004) and the Fundamental Research Funds of Chinese Academy of Meteorological Sciences (2017Y005). The authors would like to thank Associate Professor LIU Chuntao from Texas A\&M University-Corpus Christi and Professor SUN Qinghua from the Division of Environmental Health 
Sciences, College of Public Health, Ohio State University, for their kindly help.

\section{References}

Astitha M, Lelieveld J, Abdel Kader M, et al. 2012. Parameterization of dust emissions in the global atmospheric chemistryclimate model EMAC: impact of nudging and soil properties. Atmospheric Chemistry and Physics, 12(22): 11057-11083.

Baltaci H. 2017. Spatial and temporal variation of the extreme Saharan dust event over Turkey in March 2016. Atmosphere, 8(2): 16.

Chen S Y, Huang J P, Li J X, et al. 2017. Comparison of dust emissions, transport, and deposition between the Taklimakan Desert and Gobi Desert from 2007 to 2011. Science China Earth Sciences, 60(7): 1338-1355.

Cheng N, Chen T, Zhang D, et al. 2015. Air quality characteristics in Beijing during Spring Festival in 2015. Environmental Science, 36(9): 3150-3158.

China Meteorological Administration. 1979. China Meteorological Administration criterion of surface meteorological observation. Beijing: Meteorological Press, 21-27. (in Chinese)

Dickhut R M, Canuel E A, Gustafson K E, et al. 2000. Automotive sources of carcinogenic polycyclic aromatic hydrocarbons associated with particulate matter in the Chesapeake Bay region. Environmental Science and Technology, 34(21): 4635-4640.

Feng X Y, Wang S G, Cheng Y F, et al. 2010. Climatic characteristics of dust storms in the middle and west of northern China. Journal of Desert Research, 30(2): 394-399. (in Chinese)

Feng X Y, Wang S G, Yang D B, et al. 2011. Influence of dust events on $\mathrm{PM}_{10}$ pollution in key environmental protection cities of northern China during recent years. Journal of Desert Research, 31(3): 735-740. (in Chinese)

Gao W D, Jiang W. 2002. The form and hazard of sand-dust storm in Western and Southern of Taklimakan Desert. Journal of Arid Land Resources and Environment, 16(3): 64-70. (in Chinese)

Guan Q Y, Yang J, Zhao S L, et al. 2014. Climatological analysis of dust storms in the area surrounding the Tengger Desert during 1960-2007. Climate Dynamis, 45(3-4): 903-913.

Guan Q, Sun X, Yang J, et al. 2017. Dust storms in northern China: Long-term spatiotemporal characteristics and climate controls. Journal of Climate, 30(17): 6683-6700.

Khuzestani R B, Schauer J J, Wei Y, et al. 2017. Quantification of the sources of long-range transport of $\mathrm{PM}_{2.5}$ pollution in the Ordos region, Inner Mongolia, China. Environmental Pollution, 229: 1019-1031.

Liu K L, Chen T Z, Feng Z, et al. 2008. The application of $\mathrm{PM}_{10}$ in the dust events observation classification. Inner Mongolia Meteorology, 5: 8-9. (in Chinese)

Park S U, Cho J H, Park M S. 2013. Analyses of high aerosol concentration events (dense haze/mist) occurred in East Asia during 10-16 January 2013 using the data simulated by the Aerosol Modeling System. International Journal of Chemistry, 03: 10-26.

Pederzolia A, Mirceaa M, Finardib S, et al. 2010. Quantification of Saharan dust contribution to PM $_{10}$ concentrations over Italy during 2003-2005. Atmospheric Environment, 44(34): 4181-4190.

Prospero J M, Collard F X, Molinié J, et al. 2014. Characterizing the annual cycle of African dust transport to the Caribbean Basin and South America and its impact on the environment and air quality. Global Biogeochemical Cycles, 29(7): 757-773.

Qian Z A, Cai Y, Liu J T, et al. 2004. Some advances in dust storm researches in northern China. Journal of Arid Land Researches and Environment, 18: 1-8. (in Chinese)

Rodríguez S, Querol X, Alastuey A, et al. 2001. Saharan dust contributions to $\mathrm{PM}_{10}$ and TSP levels in Southern and Eastern Spain. Atmospheric Environment, 35(14): 2433-2447.

Spyrou C, Kallos G, Mitsakou C, et al. 2013. Modeling the radiative effects of desert dust on weather and regional climate. Atmospheric Chemistry and Physics, 13: 5489-5504.

Wan B T, Kang X F, Zhang J H, et al. 2004. Research on classification of dust and sand storm basic on particular concentration. Environmental Monitoring in China, 20(3): 8-11. (in Chinese)

Wang S G, Yang M, Qi B, et al. 1999. Influence of sand-dust storms occurring over the Gansu Hexi district on the air pollution in Lanzhou City. Journal of Desert Research, 19(4): 354-358. (in Chinese)

Wang S G, Wang J Y, Zhou Z J, et al. 2005. Regional characteristics of three kinds of dust storm events in China. Atmospheric Environment, 39(3): 509-520.

Wang S G, Yuan W, Shang K Z. 2006. The impacts of different kinds of dust events on $\mathrm{PM}_{10}$ pollution in Northern China. Atmospheric Environment, 40(40): 7975-7982.

Wang H, Jia X. 2013. Field observations of windblown sand and dust in the Taklimakan Desert, NW China, and insights into modern dust sources. Land Degradation \& Development, 24(4): 323-333. 
Wang H, Lei Y, Chen X, et al. 2015. Technology distribution and air pollutant emissions from coal-fired boilers for industrial and residential use in Beijing-Tianjin-Hebei area. Research of Environmental Sciences, 28(10): 1510-1517.

Xiao F, Zhou C, Liao Y. 2008. Dust storms evolution in Taklimakan Desert and its correlation with climatic parameters. Journal of Geographical Sciences, 18(4): 415-424.

Xing J, Wang J, Mathur R, et al. 2017. Impacts of aerosol direct effects on tropospheric ozone through changes in atmospheric dynamics and photolysis rates. Atmospheric Chemistry and Physics, 17(16): 9869-9883.

Yang X, Shen S, Yang F, et al. 2016. Spatial and temporal variations of blowing dust events in the Taklimakan Desert. Theoretical and Applied Climatology, 125(3-4): 669-677.

Zhang X X, Sharratt B, Chen X, et al. 2017. Dust deposition and ambient $\mathrm{PM}_{10}$ concentration in northwest China: spatial and temporal variability. Atmospheric Chemistry and Physics, 17: 1699-1711.

Zhao X J, Zhao P S, Xu J, et al. 2013. Analysis of a winter regional haze event and its formation mechanism in the North China Plain. Atmospheric Chemistry and Physics, 13(11): 5685-5696.

Zhuang G, Guo J, Yuan H, et al. 2001. The compositions, sources, and size distribution of the dust storm from China in spring of 2000 and its impact on the global environment. Chinese Science Bulletin, 46(11): 895-900.

Zu R P, Zhang K C, Qu J J. 2005. The intensity of sand-drift activities in Taklimakan Desert. Geographical Research, 24(5): 690707. (in Chinese) 